\title{
Therapeutic drug monitoring of meropenem and piperacilin administered in continuous infusion. preliminary data
}

\author{
M Miralbés Torner ${ }^{1 *}$, F Ahmad Diaz², S Carvalho Brugger ${ }^{1}$, SM Cano Marron ${ }^{1}$, JA Schoenenberger ${ }^{1}$, \\ A Aragones Eroles ${ }^{2}$, X Nuvials Casals ${ }^{1}$, M Vallverdu Vidal', B Balsera Garrido ${ }^{1}$, M Palomar Martinez ${ }^{1}$
}

From ESICM LIVES 2015

Berlin, Germany. 3-7 October 2015

\section{Introduction}

Piperacilin-tazobactam (TZP) and meropenem (MER) are two extended-spectrum beta-lactams antibiotics (ATB) broadly used in intensive care units. We know that early and appropriate ATB treatment remains the most important intervention in septic patients, so optimization of ATB administration should be a priority.

\section{Objectives}

Evaluate the effectiveness of MER and TZP administered in continuous infusion in critically ill patients in order to maintain concentrations 4-6 times above the minimum inhibitory concentration (MIC) for $100 \%$ of the interval time of infusion.

\section{Methods}

Open, prospective, single-center study. All consecutive patients in whom treatment with MER or TZP was indicated from October 2014 to March 2015 were included. A $2 \mathrm{~g}$ (MER) or $4 \mathrm{~g}$ (TZP) loading dose was given followed by a $6 \mathrm{~g}$ (MER) or 16-24g (TZP) continuous infusion over 24 hours. Serum concentrations were determined by high-performance liquid chromatography (HLPC) 1 hour, 24 hours and 3-5 days after the start of the infusion, determining maximum $(\mathrm{Cmax})$ and free steady state concentrations ( $f$ Css). The objective was maintaining $f$ Css 4-6 times above the MIC corresponding to the clinical breakpoint for Pseudomonas aeruginosa from our hospital database: $8 \mu \mathrm{g} / \mathrm{ml}$ for MER and $16 / 4 \mu \mathrm{g} / \mathrm{ml}$ for TZP. When the target was not achieved, the dose was adjusted.

${ }^{1}$ Hospital Universitari Arnau de Vilanova, Lleida, Spain

Full list of author information is available at the end of the article

\section{Results}

We enrolled 49 patients (73\% male and $27 \%$ female) and determined 60 Css. Mean APACHE-II score was $16 \pm 7$. Empiric therapy was administered in 48 cases $(80 \%)$. 13 patients $(26 \%)$ were admitted to ICU after $\geq 7$ days of hospitalization. 25 patients (51\%) had septic shock, $2(4 \%)$ severe sepsis and 1 (43\%) sepsis. 1 patient (2\%) had not systemic inflammatory response (SIR). 9 patients (18\%) had bacteremia. We analyzed Css of MER/TZP during the first 24-48 hours, which are shown in Table1. Css determination led to the dose titration in $30 \%$ of the treatments.

\section{Conclusions}

Although ATB optimization, 32\% of patients did not achieve our outcome. Therapeutic drug monitoring allows us to adjust dose administrated based on Css in order to achieve optimal drug exposure for an individual patient. Based on our results, dosages needed in critically ill patients might be markedly higher than those currently administered. We remark the need to keep analyzing cases to assess risk factors for ATB underdosing and continue monitoring Css to evaluate further dose adjustments.

\section{Grants}

Grant of the Insitut de Recerca Biomédica de Lleida (IRB).

\section{Authors' details}

${ }^{1}$ Hospital Universitari Arnau de Vilanova, Lleida, Spain. ${ }^{2}$ Hospital Universitari Arnau de Vilanova. IRB Lleida, Lleida, Spain.

Published: 1 October 2015
C 2015 Miralbés Torner et al.; This is an Open Access article distributed under the terms of the Creative Commons Attribution License (http://creativecommons.org/licenses/by/4.0), which permits unrestricted use, distribution, and reproduction in any medium, provided the original work is properly cited. 
Table 1. Css within the first 24-48 hours

\begin{tabular}{lllll}
\hline antibiotic & Cases & CSs < 4MIC & fCss 4-10 MIC & fCss >10 IMC \\
\hline Meropenem 2 g & 14 & $6(43 \%)$ & $7(50 \%)$ & $1(7 \%)$ \\
\hline Piperacilin-tazobactam 16g & 15 & $2(13 \%)$ & $9(60 \%)$ & $4(27 \%)$ \\
\hline Piperacilin-tazobactam 24g & 31 & $11(35 \%)$ & $16(52 \%)$ & $4(13 \%)$ \\
\hline Total & 60 & $19(32 \%)$ & $32(53 \%)$ & $9(15 \%)$ \\
\hline
\end{tabular}

\section{Reference}

1. Roberts JA, et al: Therapeutic drug monitoring of $\beta$-lactams in critically ill patients: proof of concept. Int J Antimicrob Agents 2010, 36(4):332-9, Oct.

doi:10.1186/2197-425X-3-S1-A394

Cite this article as: Miralbés Torner et al:: Therapeutic drug monitoring

of meropenem and piperacilin administered in continuous infusion.

preliminary data. Intensive Care Medicine Experimental 2015 3(Suppl 1):

A394.

\section{Submit your manuscript to a SpringerOpen ${ }^{\mathcal{D}}$ journal and benefit from:}

- Convenient online submission

- Rigorous peer review

- Immediate publication on acceptance

- Open access: articles freely available online

- High visibility within the field

- Retaining the copyright to your article 